\title{
The Insomnia-Addiction Positive Feedback Loop: Role of the Orexin System
}

\author{
Jennifer E. Fragale ${ }^{a} \quad$ Morgan H. James ${ }^{a} \quad$ Jorge A. Avila ${ }^{a}$ \\ Andrea M. Spaeth $^{\mathrm{b}}$ R. Nisha Aurorac ${ }^{\mathrm{c}}$ Daniel Langleben ${ }^{\mathrm{d}}$ \\ Gary Aston-Jones ${ }^{a}$ \\ ${ }^{a}$ Brain Health Institute, Rutgers Biomedical Health Sciences, Rutgers University, Piscataway, NJ, USA; \\ ${ }^{b}$ Department of Kinesiology and Health, Rutgers University, New Brunswick, NJ, USA; ' $D e p a r t m e n t ~ o f$ \\ Medicine, Robert Wood Johnson Medical School, Rutgers University, New Brunswick, NJ, USA; ${ }^{\mathrm{d}}$ Department of \\ Psychiatry, University of Pennsylvania, Philadelphia, PA, USA
}

\begin{abstract}
Significant sleep impairments often accompany substance use disorders (SUDs). Sleep disturbances in SUD patients are associated with poor clinical outcomes and treatment adherence, emphasizing the importance of normalizing sleep when treating SUDs. Orexins (hypocretins) are neuropeptides exclusively produced by neurons in the posterior hypothalamus that regulate various behavioral and physiological processes, including sleep-wakefulness and motivated drug taking. Given its dual role in sleep and addiction, the orexin system represents a promising therapeutic target for treating SUDs and their comorbid sleep deficits. Here, we review the literature on the role of the orexin system in sleep and drug addiction and discuss the therapeutic potential of orexin receptor antagonists for SUDs. We argue that orexin receptor antagonists may be effective therapeutics for treating addiction because they target orexin's regulation of sleep (top-down) and motivation (bottom-up) pathways.
\end{abstract}

(C) 2021 The Author(s)

Published by S. Karger AG, Basel

\section{Introduction}

Emerging evidence demonstrates that individuals suffering from substance use disorders (SUDs) report significant sleep impairments, including insomnia [1-3]. Indeed, an estimated $70 \%$ of patients entering detoxification treatment complain of sleep issues [4], and those who report issues are at increased risk for relapse [5]. Individuals with SUDs also report using drugs to improve sleep quality $[4,6,7]$, further emphasizing the importance of treating sleep disturbances in SUD patients. 
There is significant interest in the hypothalamic orexin (hypocretin) system as a potential novel target for medications designed to treat SUDs. Indeed, in 2019, the National Institute of Drug Abuse added orexin receptor (OxR) antagonists to their list of mostwanted medications for the treatment of opioid addiction [8]. Although this interest is largely driven by preclinical studies indicating that orexin neurons are critically involved in translating motivational states into action (i.e., bottom-up processes) [9], we argue that blockade of this system may also reduce drug craving via improvement of sleep outcomes and executive functioning in SUD patients (i.e., "top-down" processes). Here, were outline the most up-to-date evidence implicating the orexin system in these two separate addiction mechanisms. Notably, we provide only a brief overview of the orexin system in sleep and wakefulness, as this topic is described in detail elsewhere in this volume.

\section{The Role of the Orexin System in Sleep and Wakefulness}

Orexin-A and orexin-B (also known as hypocretin-1 and hypocretin-2) are neuropeptides exclusively produced by neurons in the posterior hypothalamus that regulate a wide range of behaviors by directly acting on two G-coupled protein receptors, orexin-1 $\left(\mathrm{OX}_{1} \mathrm{R}\right)$ and orexin-2 $\left(\mathrm{OX}_{2} \mathrm{R}\right)$ receptors [10]. Orexins were initially recognized as modulators of sleepwakefulness after the demonstration that narcoleptic dogs have a mutation in the $\mathrm{OX}_{2} \mathrm{R}$ [11], and that orexin knockout mice exhibited signs of the sleep disorder narcolepsy [12]. These results were extended by subsequent studies demonstrating that human narcoleptics expressed fewer orexin neurons than healthy controls [13]. Treatments that increase orexin peptide expression (e.g., chronic morphine) have been shown to reverse signs of narcolepsy in orexin-deficient mice [14], further demonstrating a role for orexin in sleepwakefulness.

Orexins primarily signal wakefulness through the $\mathrm{OX}_{2} \mathrm{R}$. Mice lacking the $\mathrm{OX}_{2} \mathrm{R}$ gene exhibit signs of narcolepsy [15] and an $\mathrm{OX}_{2} \mathrm{R}$ antagonist promotes sleep in mice and humans [16]. Likewise, mutations of the $\mathrm{OX}_{2} \mathrm{R}$ gene contributes to canine narcolepsy [11]. In line with these data, several OXR antagonists (either $\mathrm{OX}_{2} \mathrm{R}$ selective or dual) are the subject of ongoing clinical trials for the treatment of insomnia.

\section{The Role of the Orexin System in Drug Motivation}

Our laboratory was the first to implicate the orexin system in drug reward, showing that lateral hypothalamic (LH) orexin neurons in rats were Fos-activated in proportion to morphine preference in a conditioned place preference (CPP) paradigm [17]. We also found that stimulation of $\mathrm{LH}$ orexin neurons reinstated extinguished morphine CPP, and that this effect was blocked by the selective $\mathrm{OX}_{1} \mathrm{R}$ antagonist SB-334867 [17]. Since then, $\mathrm{OX}_{1} \mathrm{R}$ antagonists have been shown to attenuate addiction-like behaviors across most drugs of abuse, including alcohol, cocaine, opioids, and nicotine (for review see [9]).

An increase in orexin cell number and activity occurs during paradigms that increase addiction behavior [18-20]. For example, orexin mRNA (detected via in situ hybridization) is increased in alcohol-preferring rats following chronic exposure to alcohol [19]. We found that self-administration paradigms that increase motivation for cocaine or fen- 
Fig. 1. Schematic illustrating proposed positive feedback loops linking orexin plasticity, insomnia, and addiction.

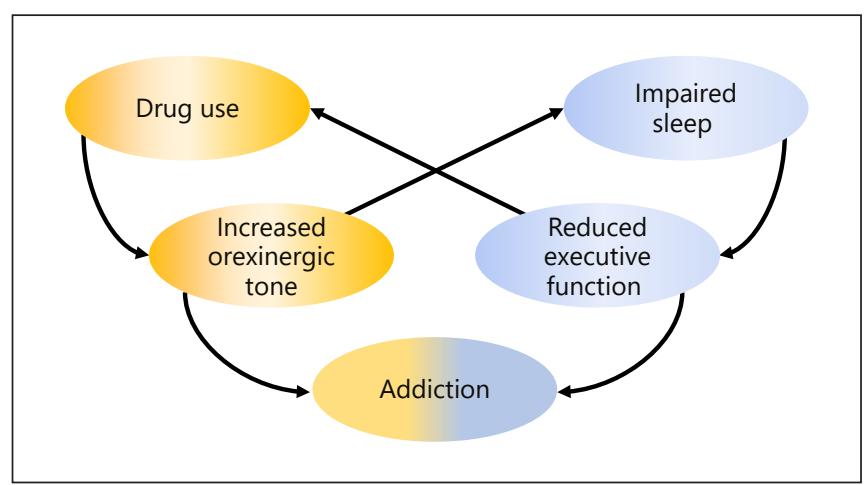

tanyl in rats are associated with greater numbers of orexin-expressing neurons detected by immunohistochemistry (IHC) [20,21]. Increased orexin expression is also seen with other opioids; for example, orexin protein levels are increased in mice chronically given morphine and in the postmortem brain tissue of heroin addicts [14].

The role of the orexin system in addiction is not limited to drug taking. Orexins have also been shown to regulate drug withdrawal behaviors, particularly with respect to opioid withdrawal. In rodents, morphine withdrawal increased orexin gene transcription as well as the activity of orexin neurons (indicated by IHC detection of Fos) [15]. Physical signs of morphine withdrawal were attenuated in orexin knockout mice [15] and by $\mathrm{OX}_{1} \mathrm{R}$ antagonism $[22,23]$. In addition, $\mathrm{OX}_{1} \mathrm{R}$ antagonism has been shown to reduce withdrawalinduced increases in Fos expression in several brain areas [22, 23].

Importantly in the context of drug-seeking, the orexin system also plays a role in stress regulation. Stress is a major contributing factor to the development and maintenance of SUDs [24-26], and stress relief is a common cause of initial substance misuse in healthy individuals [27]. In animals, stress facilitates the acquisition of drug self-administration [28], craving [29], and reinstatement of extinguished drug-seeking [26]. Orexins play a critical role in modulating behavioral and physiological responses to stress, particularly concerning stress-elicited drug-seeking. For example, compounds that block orexin signaling are highly effective at reducing stress-elicited seeking of opioids [30], stimulants [31], and alcohol [32]. Given the fundamental role of stress in drug addiction, OXR antagonists may effectively treat SUDs by decreasing relapse associated with stressful life events.

\section{An Addiction-Insomnia Positive Feedback Loop?}

The relationships reviewed above among orexin signaling, insomnia, and drug motivation indicate a possible self-reinforcing feedback loop between insomnia and addiction linked by plasticity in orexin neurons (Fig. 1). In this hypothesis, drug use increases orexin expression and signaling, which both interferes with sleep and in parallel drives a hyper- 
motivated state. Insomnia caused by elevated orexin also degrades executive function which compromises attempts at drug abstinence. Continued drug exposure further increases orexin signaling and the consequent insomnia, hyper-motivation and compromised executive function, creating a vicious cycle that perpetuates the addiction-insomnia problem via orexin hyper-signaling.

In line with this hypothesis, we propose that OxR antagonists might be ideal for breaking this loop. By decreasing orexin signaling, an orexin antagonist can limit insomnia and hyper-motivation, and perhaps also limit the plasticity response in orexin neurons that otherwise increases orexin signaling.

\section{Dual Orexin Antagonists and Selective $\mathrm{OX}_{2} \mathrm{R}$ Antagonists Facilitate Sleep/Treat Sleep Dysfunction}

Evidence that signaling via the $\mathrm{OX}_{2} \mathrm{R}$ promotes waking (as reviewed above) indicates that compounds that block signaling at $\mathrm{OX}_{2}$ Rs might improve sleep. The first wave of such compounds designed to treat sleep dysregulation were developed to block signaling at both $\mathrm{OX}_{1} \mathrm{R}$ and $\mathrm{OX}_{2} \mathrm{R}$, as preclinical studies indicated that better sleep outcomes were achieved with dual versus selective blockade [33]. As of mid-2021, two compounds, suvorexant (Belsomra ${ }^{\mathrm{TM}}$, Merck Inc.) and lemborexant (Dayvigo ${ }^{\mathrm{TM}}$, Esai Inc.), have received approval from the US Food and Drug Administration (FDA) for the treatment of insomnia. Suvorexant and lemborexant have been shown to improve both objective and subjective sleep measures, including reducing Insomnia Severity Index scores and increasing sleep duration $[34,35]$. In addition, both medications have been found to be well-tolerated with minimal side effects. Daridorexant (Idorsia Pharmaceuticals Ltd), another dual orexin antagonist (DORA), showed promise in Phase 3 trials [36] improving night-time sleep and daytime functioning, and its New Drug Application has been submitted to the FDA for review in January 2021. Recently, there has been some interest in the development of selective $\mathrm{OX}_{2} \mathrm{R}$ antagonists (2-SORAs), including seltorexant (Minerva NeuroSciences and Janssen Pharmaceuticals), which Phase 2 clinical trials have revealed to improve sleep quality in patients with insomnia alone or comorbid with major depressive disorder $[37,38]$; a Phase 3 clinical development program is currently ongoing.

\section{$\mathrm{OX}_{1} R$ Signaling Drives Motivation for Drug Rewards: Implications for Addiction Therapeutics}

As discussed above, $\mathrm{OX}_{1} \mathrm{R}$ signaling promotes addiction-related behaviors across numerous drugs of abuse $[17,39,40]$, indicating that selective $\mathrm{OX}_{1} \mathrm{R}$ antagonists (1-SORAs) may be effective in treating SUDs in clinical populations. The orexin system seems to play a universal role in cue-induced reward seeking. Orexin neurons are activated in response to drug-associated cues and contexts $[9,17,20]$. This is consistent with previously published reports showing that the $\mathrm{OX}_{1} \mathrm{R}$ is necessary for cue-induced reinstatement of seeking for heroin, remifentanil, cocaine, ethanol, nicotine, and sucrose [40-44]. Interestingly, our work, and that of others, indicate that 1-SORAs may be particularly useful in treating individuals with the most severe cases of addiction. We showed that $\mathrm{OX}_{1} \mathrm{R}$ block- 
Table 1. Clinical trials of orexin receptor antagonists for the treatment of substance abuse disorders

\begin{tabular}{|c|c|c|c|}
\hline Title of trial & Status & Conditions & $\begin{array}{l}\text { ClinicalTrials.gov } \\
\text { Identifier }\end{array}$ \\
\hline $\begin{array}{l}\text { Medication Development in Alcoholism: } \\
\text { Suvorexant versus Placebo }\end{array}$ & Not yet recruiting & Alcohol use disorder & NCT04229095 \\
\hline $\begin{array}{l}\text { Suvorexant in the Management } \\
\text { Comorbid Sleep Disorder and Alcohol } \\
\text { Dependence }\end{array}$ & Recruiting & Alcohol use disorder & NCT03897062 \\
\hline Suvorexant and Cocaine & Recruiting & Cocaine use disorder & NCT03937986 \\
\hline $\begin{array}{l}\text { Role of the Orexin Receptor System in } \\
\text { Stress, Sleep and Cocaine Use }\end{array}$ & Completed & $\begin{array}{l}\text { Cocaine use disorder/ } \\
\text { Anxiety }\end{array}$ & NCT02785406 \\
\hline $\begin{array}{l}\text { Medical Management of Sleep } \\
\text { Disturbance During Opioid Tapering }\end{array}$ & Recruiting & Opioid use disorder & NCT03789214 \\
\hline $\begin{array}{l}\text { Examining the Role of the Orexin System } \\
\text { in Sleep and Stress in Persons with } \\
\text { Opioid Use Disorder }\end{array}$ & Recruiting & Opioid use disorder & NCT04287062 \\
\hline $\begin{array}{l}\text { Dual-Orexin Antagonism as a Mechanism } \\
\text { for Improving Sleep and Drug } \\
\text { Abstinence in Opioid Use Disorder }\end{array}$ & Recruiting & Opioid use disorder & NCT04262193 \\
\hline $\begin{array}{l}\text { The Efficacy of Suvorexant in Treatment } \\
\text { of Patients with Substance Use Disorder } \\
\text { and Insomnia: A Pilot Open Trial }\end{array}$ & $\begin{array}{l}\text { Enrolling by } \\
\text { invitation }\end{array}$ & $\begin{array}{l}\text { Opioid use disorder } \\
\text { Alcohol use disorder }\end{array}$ & NCT03412591 \\
\hline $\begin{array}{l}\text { Suvorexant to Reduce Symptoms of } \\
\text { Nicotine Use }\end{array}$ & Not yet recruiting & Nicotine dependence & NCT04234997 \\
\hline $\begin{array}{l}\text { Targeting Orexin to Treat Nicotine } \\
\text { Dependence }\end{array}$ & Recruiting & Nicotine dependence & NCT03999099 \\
\hline
\end{tabular}

A ClinicalTrials.gov search (accessed on Jan 1, 2021) yielded ten trials of orexin system modulators for substance use disorders at different stages of progress in the US and Australia, as listed here.

ade selectively reduced home-cage ethanol drinking and self-administration in high-alcohol-preferring rats $[43,45]$. Using a behavioral economics task, we found that the selective $\mathrm{OX}_{1} \mathrm{R}$ antagonist SB-334867 preferentially decreased motivation for cocaine and fentanyl in rats with the strongest demand for these drugs [46, 47]. Rats highly motivated for cocaine or fentanyl were also sensitive to lower doses of SB-334867 than rats with a milder addiction phenotype $[20,21,48]$. $\mathrm{OX}_{1}$ Rs antagonists are generally non-sedating at doses that reduce drug-seeking $[20,47,49]$, and thus likely attenuate addiction behaviors by directly attenuating a hyperresponsive orexin motivational system. There are currently no FDA-approved 1-SORAs for clinical use; however, several candidates are in development, e.g., ACT-539313 and JNJ-61393215.

Collectively, this evidence supports the use of DORAs (or 2-SORA) to treat sleep disturbances and 1-SORA to attenuate hyper-motivation. Although there are currently no FDA-approved 1-SORAs, we argue that DORAs represent an attractive therapeutic for SUDs as they are effective in improving sleep and are likely to attenuate addiction behav- 
iors via inhibiting $\mathrm{OX}_{2} \mathrm{R}$ and $\mathrm{OX}_{1} \mathrm{R}$ signaling, respectively. Indeed, we note that several clinical studies are currently ongoing to determine the efficacy of these compounds for improving both sleep and craving outcomes in SUDs (Table 1). While we applaud these efforts, below we outline key considerations that should be addressed with respect to the clinical use of DORAs in SUD populations.

\section{Advantages, Limitations, and Future Considerations regarding DORAs as Addiction Therapeutics}

Current treatment avenues for individuals with comorbid addiction and sleep disorders are very limited, highlighting the need for alternative therapeutics. Benzodiazepines are rarely used as sleep therapeutics in SUD patients due to their abuse potential and ability to compromise respiration. This is especially important for opioid patients as opioids also decrease respiratory function. Although prepro-orexin-knockout mice exhibit attenuated hypercapnic chemoreflexes compared to wild-type animals [50], human studies have demonstrated a diminished hypoxic respiratory response only in narcoleptic patients with the HLA-DQB1*0602 allele [51]. This indicates that the association with compromised respiratory function is more tightly aligned with the specific allele rather than an orexin deficiency. Thus, it is not surprising that, unlike commonly prescribed sedative-hypnotic agents, such as benzodiazepines and the non-benzodiazepine " $Z$ " drugs, DORAs such as FDA-approved suvorexant and lemborexant are not associated with clinically significant adverse respiratory outcomes during sleep $[52,53]$. Therefore, DORAs may offer a safer sleep-related respiratory profile, especially for persons taking opioids who are already at risk for sleep-disordered breathing [54]. We note, however, that the effect of DORAs on respiratory outcomes is yet to be examined in patients with opioid use disorder or who are also under opioid substitution therapy; these experiments will be important for determining the suitability of these compounds for this population.

Although animal studies indicate no abuse potential of DORAs such as suvorexant [55], humans with a history of polysubstance abuse report higher "liking" for suvorexant compared to placebo [56]. This finding raises the possibility that a history of drug abuse might increase suvorexant's abuse liability. Accordingly, suvorexant and lemborexant are designated by the Drug Enforcement Administration (DEA) of the US as Schedule IVcontrolled substances; however, we note that further studies are necessary to fully examine the abuse potentials of DORAs, particularly in individuals with a history of substance abuse.

Although DORAs appear to be an attractive therapeutic strategy for addiction, there are several key questions that need to be addressed. A first step is to test the effectiveness of DORAs in attenuating addiction-like behaviors such as drug taking, relapse, craving, and withdrawal in preclinical models across multiple drug classes. To date, only a small number of preclinical studies have tested the efficacy of a DORA on addiction-like behaviors. Two studies in rats indicated that suvorexant reduced the motivational properties of cocaine and improved cocaine-induced deficits in impulsive behavior [57, 58]. We reported that suvorexant decreased motivation for fentanyl on a behavioral economics task, 
an effect that was greatest in rats with the highest motivation for fentanyl [59]. A preliminary randomized clinical study indicated that suvorexant reduced several relapse-related indices in patients with cocaine use disorder [60]. Although these results are promising, future studies are necessary to further test the efficacy of DORAs for SUDs.

Second, DORA dosing should be optimized to simultaneously maximize its sleep-promoting effects and anti-craving properties. Bedtime dosing of DORAs to induce sleep results in limited bioavailability the following day when the opportunity for drug use is high [61]. We reported that the anti-drug-seeking effects of suvorexant and the selective $\mathrm{OX}_{1} \mathrm{R}$ antagonist SB-334867 extend beyond their bioavailability (up to $48 \mathrm{~h}$ post-dosing) when administered to rats during the active period $[59,62]$; it will be important to test whether this is also the case when given at the onset of the inactive period. An alternative approach might be combining a DORA at bedtime with a selective $\mathrm{OX}_{1} \mathrm{R}$ antagonist (such as those in development, described above) in the morning.

The orexin system is important for facilitating a range of motivated behaviors, and thus chronic suppression of orexin signaling might promote a non-motivated or depressive state. Indeed, orexin system function is lower in both rats and patients exhibiting depression-like symptoms [63-65]. Moreover, administration of suvorexant has been linked to the worsening of depression symptoms and onset of suicidal thoughts [66] (but see [67] for antidepressant effects of seltorexant). This risk might be present in SUD given the high comorbidity of depression in these patients [68].

In addition, although clinical studies indicate minimal effects of suvorexant on memory, negative effects have been observed at high doses in elderly populations or when combined with alcohol in healthy adults $[69,70]$. We have reported that an $\mathrm{OX}_{1} \mathrm{R}$ antagonist had no effect on response inhibition in rats [49], but further characterization of potential effects of DORAs on cognition is needed.

Finally, it is important to consider potential interactive effects of DORAs as an adjunct to conventional opioid management therapies such as buprenorphine. Of note, patients prescribed suvorexant are advised against next-day driving and other activities requiring full alertness as some patients reported daytime somnolence at $9 \mathrm{~h}$ post-dosing [71]; it is unclear whether these effects would be exacerbated by concurrent buprenorphine therapy, which in itself can be sedating [72]. Moreover, although suvorexant has not been found to have adverse respiratory effects in clinical trials $[53,73,74]$, this has not been tested in the presence of opioids such as buprenorphine that can also have respiratory suppressing effects [75-77].

Although these are relevant considerations, there are reasons to hypothesize that they will not seriously impede the use of DORAs to treat SUDs. Importantly, for each of these considerations, we found that suvorexant and other OxR antagonists are effective at suppressing drug-seeking at lower doses in animals that exhibit a strong addiction phenotype than in animals with more moderate addition-like behaviors [20, 21, 46, 59]. Thus, the potential deleterious effects outlined here might be circumvented by prescribing lower doses of a DORA than what is required in a non-SUD population; of course, this possibility would need to be tested more thoroughly in both preclinical and clinical studies. 


\section{Conclusion}

As summarized above, orexin receptor antagonists show promise as a novel treatment for SUDs. Specifically, we propose that DORAs may be effective at treating SUDs by simultaneously suppressing drug craving ("bottom-up" processes) and improving sleep outcomes and executive functioning ("top-down” processes). As we have outlined, there are several important questions that need to be addressed in order to help realize this potential and confirm both the safety and efficacy profile of DORAs in treating addiction.

\section{Key Take-Home Points}

- Sleep impairments are comorbid in individuals with substance abuse disorders.

- There is a positive feedback loop where drug intake causes increased orexin signaling, which in turn increases motivation for drug and impairs sleep and executive function, causing further drug intake.

- Orexin receptor antagonists can break the cycle between drug use, motivation and sleep deficits.

\section{Conflict of Interest Statement}

G.A.J. consults for Merck Pharmaceuticals and Idorsia Pharmaceuticals. The other authors declare no potential conflicts of interest.

\section{Funding Sources}

This work was supported by USPHS awards R01-DA006214, K99-DA045765, and K12-GM093854.

\section{Author Contributions}

All authors were involved in the development and review of the chapter, approved the final version to be published, and take responsibility for all aspects of the work.

\section{References}

1 Eacret D, Veasey SC, Blendy JA: Bidirectional relationship between opioids and disrupted sleep: putative mechanisms. Mol Pharmacol 2020;98:445-453.

2 Koob GF, Colrain IM: Alcohol use disorder and sleep disturbances: a feed-forward allostatic framework. Neuropsychopharmacology 2020;45:141-165.

3 Valentino RJ, Volkow ND: Drugs, sleep, and the addicted brain. Neuropsychopharmacology 2020;45:3-5.

4 Angarita GA, Emadi N, Hodges S, Morgan PT: Sleep abnormalities associated with alcohol, cannabis, cocaine, and opiate use: a comprehensive review. Addict Sci Clin Pract 2016;11:9.
5 Kaplan KA, McQuaid J, Primich C, Rosenlicht N: An evidence-based review of insomnia treatment in early recovery. J Addict Med 2014;8:389-394.

6 Chakravorty S, Vandrey RG, He S, Stein MD: Sleep management among patients with substance use disorders. Med Clin North Am 2018;102:733-743.

7 Sullivan MD: Depression effects on long-term prescription opioid use, abuse, and addiction. Clin J Pain 2018; $34: 878-884$ 
8 Rasmussen K, White DA, Acri JB: NIDA's medication development priorities in response to the Opioid Crisis: ten most wanted. Neuropsychopharmacology 2019;44: 657-659.

9 James MH, Mahler SV, Moorman DE, Aston-Jones G: A decade of orexin/hypocretin and addiction: where are we now? Curr Top Behav Neurosci 2017;33:247-281.

10 Sakurai T, Amemiya A, Ishii M, Matsuzaki I, Chemelli $\mathrm{RM}$, Tanaka H, et al: Orexins and orexin receptors: a family of hypothalamic neuropeptides and $\mathrm{G}$ proteincoupled receptors that regulate feeding behavior. Cell 1998;92:573-585.

11 Lin L, Faraco J, Li R, Kadotani H, Rogers W, Lin X, et al: The sleep disorder canine narcolepsy is caused by a mutation in the hypocretin (orexin) receptor 2 gene. Cell 1999;98:365-376.

12 Chemelli RM, Willie JT, Sinton CM, Elmquist JK, Scammell T, Lee C, et al: Narcolepsy in orexin knockout mice: molecular genetics of sleep regulation. Cell 1999;98: 437-451.

13 Thannickal TC, Nienhuis R, Siegel JM: Localized loss of hypocretin (orexin) cells in narcolepsy without cataplexy. Sleep 2009;32:993-998.

14 Thannickal TC, John J, Shan L, Swaab DF, Wu MF, Ramanathan L, et al: Opiates increase the number of hypocretin-producing cells in human and mouse brain and reverse cataplexy in a mouse model of narcolepsy. Sci Transl Med 2018;10.

15 Georgescu D, Zachariou V, Barrot M, Mieda M, Willie JT, Eisch AJ, et al: Involvement of the lateral hypothalamic peptide orexin in morphine dependence and withdrawal. J Neurosci 2003;23:3106-3111.

16 Gotter AL, Forman MS, Harrell CM, Stevens J, Svetnik $\mathrm{V}$, Yee KL, et al: Orexin 2 receptor antagonism is sufficient to promote NREM and REM sleep from mouse to man. Sci Rep 2016;6:27147.

17 Harris GC, Wimmer M, Aston-Jones G: A role for lateral hypothalamic orexin neurons in reward seeking. Nature 2005;437:556-559.

18 Lee MG, Hassani OK, Jones BE: Discharge of identified orexin/hypocretin neurons across the sleep-waking cycle. J Neurosci 2005;25:6716-6720.

19 Lawrence AJ, Cowen MS, Yang HJ, Chen F, Oldfield B: The orexin system regulates alcohol-seeking in rats. $\mathrm{Br} \mathrm{J}$ Pharmacol 2006;148:752-759.

20 James MH, Stopper CM, Zimmer BA, Koll NE, Bowrey HE, Aston-Jones G: Increased number and activity of a lateral subpopulation of hypothalamic orexin/hypocretin neurons underlies the expression of an addicted state in rats. Biol Psychiatry 2019;85:925-935.

21 Fragale JE, James MH, Aston-Jones G: Intermittent selfadministration of fentanyl induces a multifaceted addiction state associated with persistent changes in the orexin system. Addict Biol 2020;e12946.

22 Sharf R, Sarhan M, Dileone RJ: Orexin mediates the expression of precipitated morphine withdrawal and concurrent activation of the nucleus accumbens shell. Biol Psychiatry 2008;64:175-183.
23 Laorden ML, Ferenczi S, Pinter-Kubler B, GonzalezMartin LL, Lasheras MC, Kovacs KJ, et al: Hypothalamic orexin - a neurons are involved in the response of the brain stress system to morphine withdrawal. PLoS One 2012; 7:e36871.

24 Koob GF: Neurobiology of opioid addiction: Opponent process, hyperkatifeia, and negative reinforcement. Biol Psychiatry 2020;87:44-53.

25 Reiner DJ, Fredriksson I, Lofaro OM, Bossert JM, Shaham Y: Relapse to opioid seeking in rat models: behavior, pharmacology and circuits. Neuropsychopharmacology 2019;44:465-477.

26 Mantsch JR, Baker DA, Funk D, Le AD, Shaham Y: Stress-induced reinstatement of drug seeking: 20 years of progress. Neuropsychopharmacology 2016;41:335356.

27 O’Toole BI, Kirk R, Bittoun R, Catts SV: Combat, posttraumatic stress disorder, and smoking trajectory in a cohort of male Australian army Vietnam veterans. Nicotine Tob Res 2018;20:1198-1205.

28 Piazza PV, Le Moal M: The role of stress in drug selfadministration. Trends Pharmacol Sci 1998;19:67-74.

29 Lu L, Grimm JW, Hope BT, Shaham Y: Incubation of cocaine craving after withdrawal: a review of preclinical data. Neuropharmacology 2004;47:214-226.

30 Qi K, Wei C, Li Y, Sui N: Orexin receptors within the nucleus accumbens shell mediate the stress but not drug priming-induced reinstatement of morphine conditioned place preference. Front Behav Neurosci 2013;7:144.

31 Boutrel B, Kenny PJ, Specio SE, Martin-Fardon R, Markou A, Koob GF, et al: Role for hypocretin in mediating stress-induced reinstatement of cocaine-seeking behavior. Proc Natl Acad Sci USA 2005;102:19168-19173.

32 Richards JK, Simms JA, Steensland P, Taha SA, Borgland SL, Bonci A, et al: Inhibition of orexin-1/hypocretin-1 receptors inhibits yohimbine-induced reinstatement of ethanol and sucrose seeking in Long-Evans rats. Psychopharmacology (Berl) 2008;199:109-117.

33 Winrow CJ, Gotter AL, Cox CD, Doran SM, Tannenbaum PL, Breslin MJ, et al: Promotion of sleep by suvorexant - a novel dual orexin receptor antagonist. J Neurogenet 2011;25:52-61.

34 Herring WJ, Connor KM, Ivgy-May N, Snyder E, Liu K, Snavely DB, et al: Suvorexant in patients with insomnia: results from two 3-month randomized controlled clinical trials. Biol Psychiatry 2016;79:136-148.

35 Rosenberg R, Murphy P, Zammit G, Mayleben D, Kumar D, Dhadda S, et al: Comparison of lemborexant with placebo and zolpidem tartrate extended release for the treatment of older adults with insomnia disorder: a phase 3 randomized clinical trial. JAMA Netw Open 2019;2:e1918254.

36 Roth T, Zammit G, Mignot E, Leger D, Bassetti C, Pain $S$, et al: P167. Daridorexant, a novel dual orexin receptor antagonist, delivers significant improvement in sleep parameters and daytime function for patients with insomnia disorder. J Sleep Res 2020;29(S1):e13181. 
37 Brooks S, Jacobs GE, de Boer P, Kent JM, Van Nueten L, van Amerongen G, et al: The selective orexin-2 receptor antagonist seltorexant improves sleep: an exploratory double-blind, placebo controlled, crossover study in antidepressant-treated major depressive disorder patients with persistent insomnia. J Psychopharmacol 2019;33:202-209.

38 De Boer P, Drevets WC, Rofael H, van der Ark P, Kent JM, Kezic I, et al: A randomized Phase 2 study to evaluate the orexin-2 receptor antagonist seltorexant in individuals with insomnia without psychiatric comorbidity. J Psychopharmacol 2018;32:668-677.

39 Prince CD, Rau AR, Yorgason JT, Espana RA: Hypocretin/orexin regulation of dopamine signaling and cocaine self-administration is mediated predominantly by hypocretin receptor 1. ACS Chem Neurosci 2015;6:138-146.

40 Smith RJ, See RE, Aston-Jones G: Orexin/hypocretin signaling at the orexin 1 receptor regulates cue-elicited cocaine-seeking. Eur J Neurosci 2009;30:493-503.

41 Porter-Stransky KA, Bentzley BS, Aston-Jones G: Individual differences in orexin-I receptor modulation of motivation for the opioid remifentanil. Addict Biol 2017;22:303-317.

42 Smith RJ, Aston-Jones G: Orexin/hypocretin 1 receptor antagonist reduces heroin self-administration and cueinduced heroin seeking. Eur J Neurosci 2012;35:798804.

43 Moorman DE, James MH, Kilroy EA, Aston-Jones G: Orexin/hypocretin-1 receptor antagonism reduces ethanol self-administration and reinstatement selectively in highly-motivated rats. Brain Res 2017;1654(Pt A):34-42.

44 Plaza-Zabala A, Flores A, Maldonado R, Berrendero F: Hypocretin/orexin signaling in the hypothalamic paraventricular nucleus is essential for the expression of nicotine withdrawal. Biol Psychiatry 2012;71:214-223.

45 Moorman DE, Aston-Jones G: Orexin-1 receptor antagonism decreases ethanol consumption and preference selectively in high-ethanol-preferring Sprague-Dawley rats. Alcohol 2009;43:379-386.

46 James MH, Bowrey HE, Stopper CM, Aston-Jones G: Demand elasticity predicts addiction endophenotypes and the therapeutic efficacy of an orexin/hypocretin-1 receptor antagonist in rats. Eur J Neurosci 2019;50: 2602-2612.

47 Fragale JE, Pantazis CB, James MH, Aston-Jones G: The role of orexin-1 receptor signaling in demand for the opioid fentanyl. Neuropsychopharmacology 2019;44: 1690-1697.

48 Schmeichel BE, Herman MA, Roberto M, Koob GF: Hypocretin neurotransmission within the central amygdala mediates escalated cocaine self-administration and stress-induced reinstatement in rats. Biol Psychiatry 2017;81:606-615.

49 Wiskerke J, James MH, Aston-Jones G: The orexin-1 receptor antagonist SB-334867 reduces motivation, but not inhibitory control, in a rat stop signal task. Brain Res 2020;1731:146222.
50 Deng BS, Nakamura A, Zhang W, Yanagisawa M, Fukuda Y, Kuwaki T: Contribution of orexin in hypercapnic chemoreflex: evidence from genetic and pharmacological disruption and supplementation studies in mice. J Appl Physiol (1985) 2007;103:1772-1779.

51 Han F: Respiratory regulation in narcolepsy. Sleep Breath 2012;16:241-245.

52 Cheng JY, Filippov G, Moline M, Zammit GK, Bsharat M, Hall N: Respiratory safety of lemborexant in healthy adult and elderly subjects with mild obstructive sleep apnea: a randomized, double-blind, placebo-controlled, crossover study. J Sleep Res 2020;e13021.

53 Sun H, Palcza J, Card D, Gipson A, Rosenberg R, Kryger $\mathrm{M}$, et al: Effects of suvorexant, an orexin receptor antagonist, on respiration during sleep in patients with obstructive sleep apnea. J Clin Sleep Med 2016;12:9-17.

54 Chowdhuri S, Javaheri S: Sleep disordered breathing caused by chronic opioid use: diverse manifestations and their management. Sleep Med Clin 2017;12:573586.

55 Born S, Gauvin DV, Mukherjee S, Briscoe R: Preclinical assessment of the abuse potential of the orexin receptor antagonist, suvorexant. Regul Toxicol Pharmacol 2017; 86:181-192.

56 Schoedel KA, Sun H, Sellers EM, Faulknor J, LevyCooperman N, Li X, et al: Assessment of the abuse potential of the orexin receptor antagonist, suvorexant, compared with zolpidem in a randomized crossover study. J Clin Psychopharmacol 2016;36:314-323.

57 Gentile TA, Simmons SJ, Barker DJ, Shaw JK, Espana RA, Muschamp JW: Suvorexant, an orexin/hypocretin receptor antagonist, attenuates motivational and hedonic properties of cocaine. Addict Biol 2018;23:247-255.

58 Gentile TA, Simmons SJ, Watson MN, Connelly KL, Brailoiu E, Zhang Y, et al: Effects of suvorexant, a dual orexin/hypocretin receptor antagonist, on impulsive behavior associated with cocaine. Neuropsychopharmacology 2018;43:1001-1009.

59 O'Connor SL, Fragale JE, James MH, Aston-Jones G: The dual orexin/hypocretin receptor antagonist suvorexant reduces addiction-like behaviors for the opioid fentanyl. bioRxiv 2020; 2020.04.25.061887.

60 Suchting R, Yoon JH, Miguel GGS, Green CE, Weaver MF, Vincent JN, et al: Preliminary examination of the orexin system on relapse-related factors in cocaine use disorder. Brain Res 2019;146359.

61 James MH, Fragale JE, Aurora RN, Cooperman NA, Langleben DD, Aston-Jones G: Repurposing the dual orexin receptor antagonist suvorexant for the treatment of opioid use disorder: why sleep on this any longer? Neuropsychopharmacology 2020;45:717-719.

62 Mohammadkhani A, James MH, Pantazis CB, AstonJones G: Persistent effects of the orexin-1 receptor antagonist SB-334867 on motivation for the fast acting opioid remifentanil. Brain Res 2019;146461.

63 Lutter M, Krishnan V, Russo SJ, Jung S, McClung CA, Nestler EJ: Orexin signaling mediates the antidepressant-like effect of calorie restriction. J Neurosci. 2008;28(12):3071-5. 
64 James MH, Campbell EJ, Walker FR, Smith DW, Richardson HN, Hodgson DM, et al: Exercise reverses the effects of early life stress on orexin cell reactivity in male but not female rats. Front Behav Neurosci. 2014;8:244.

65 Brundin L, Bjorkqvist M, Petersen A, Traskman-Bendz L: Reduced orexin levels in the cerebrospinal fluid of suicidal patients with major depressive disorder. Eur Neuropsychopharmacol. 2007;17(9):573-9.

66 Petrous J, Furmaga K: Adverse reaction with suvorexant for insomnia: acute worsening of depression with emergence of suicidal thoughts. BMJ Case Rep 2017; 2017:bcr2017222037.

67 Recourt K, de Boer P, Zuiker R, Luthringer R, Kent J, van der Ark P, et al: The selective orexin-2 antagonist seltorexant (JNJ-42847922/MIN-202) shows antidepressant and sleep-promoting effects in patients with major depressive disorder. Transl Psychiatry 2019;9:216.

68 Hunt GE, Malhi GS, Lai HMX, Cleary M: Prevalence of comorbid substance use in major depressive disorder in community and clinical settings, 1990-2019: systematic review and meta-analysis. J Affect Disord 2020;266: 288-304.

69 Preskorn SH: CNS drug development, lessons learned, part 5: how preclinical and human safety studies inform the approval and subsequent use of a new drug-suvorexant as an example. J Psychiatr Pract 2018;24:104-110.

70 Sun H, Yee KL, Gill S, Liu W, Li X, Panebianco D, et al: Psychomotor effects, pharmacokinetics and safety of the orexin receptor antagonist suvorexant administered in combination with alcohol in healthy subjects. J Psychopharmacol 2015;29:1159-1169.
71 Vermeeren A, Sun H, Vuurman EF, Jongen S, Van Leeuwen CJ, Van Oers AC, et al: On-the-road driving performance the morning after bedtime use of suvorexant 20 and $40 \mathrm{mg}$ : a study in non-elderly healthy volunteers. Sleep 2015;38:1803-1813.

72 Lange WR, Fudala PJ, Dax EM, Johnson RE: Safety and side-effects of buprenorphine in the clinical management of heroin addiction. Drug Alcohol Depend 1990; 26:19-28.

73 Uemura N, McCrea J, Sun H, Donikyan M, Zammit G, Liu R, et al: Effects of the orexin receptor antagonist suvorexant on respiration during sleep in healthy subjects. J Clin Pharmacol 2015;55:1093-1100.

74 Sun H, Palcza J, Rosenberg R, Kryger M, Siringhaus T, Rowe J, et al: Effects of suvorexant, an orexin receptor antagonist, on breathing during sleep in patients with chronic obstructive pulmonary disease. Respir Med 2015;109:416-426.

75 van Dorp E, Yassen A, Sarton E, Romberg R, Olofsen E, Teppema L, et al: Naloxone reversal of buprenorphineinduced respiratory depression. Anesthesiology 2006; 105:51-57.

76 Dahan A, Yassen A, Romberg R, Sarton E, Teppema L, Olofsen E, et al: Buprenorphine induces ceiling in respiratory depression but not in analgesia. Br J Anaesth 2006;96:627-632.

77 Dahan A: Opioid-induced respiratory effects: new data on buprenorphine. Palliat Med. 2006;20(suppl 1):s3-s8.

Gary Aston-Jones

Brain Health Institute, Rutgers University/Rutgers Biomedical and Health Sciences 259 SPH/RWJMS Research Building, 683 Hoes Lane West

Piscataway, NJ 08854 (USA)

gsa35@ca.rutgers.edu 